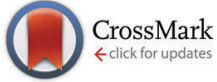

Cite this: J. Mater. Chem. C, 2016, 4, 4143

Received 11th February 2016, Accepted 12th April 2016

DOI: $10.1039 / c 6 t c 00625 f$

www.rsc.org/MaterialsC

\section{Reduced crystallinity and enhanced charge transport by melt annealing of an organic semiconductor on single layer graphene $\dagger$}

\author{
Vasyl Skrypnychuk, ${ }^{a}$ Nicolas Boulanger, ${ }^{a}$ Victor $\mathrm{Yu}^{\mathrm{b}}{ }^{\mathrm{M}}$ Michael Hilke, \\ Michael F. Toney ${ }^{c}$ and David R. Barbero*a
}

We report on the effect of the annealing temperature on the crystallization and the electrical properties of the semiconducting polymer poly(3-hexylthiophene) (P3HT) on single layer graphene. Electrical characterization showed that heating the $\mathrm{P} 3 \mathrm{HT}$ film above the melting point $\left(T_{m}\right)$ resulted in a higher vertical charge carrier mobility. Grazing incidence X-ray diffraction (GIXD) revealed that the film was actually less crystalline overall, but that it consisted of a much higher number of face-on crystallites. We moreover show that annealing above $T_{m}$ removes the existing seeds still present in the film at lower temperatures and enhances face-on formation. These results provide a better understanding of the influence of the annealing temperature on polythiophene crystallization on graphene, and it shows that the annealing at higher temperature induces a more favorable crystalline orientation which enhances charge transport, despite the reduction in the overall crystallinity. These results should help in the design of more efficient graphene based organic electronic devices by controlling the crystalline morphology of the semiconducting film.

\section{Introduction}

Due to its flexibility, chemical inertness, as well as ballistic charge transport, graphene has generated a lot of interest as a material for flexible electrodes and energy conversion devices such as a fieldeffect transistor (FET) and an organic photovoltaic (OPV) devices. ${ }^{1-4}$ Moreover, the strong $\pi$ interactions which occur between a graphene sheet and a thin layer of organic semiconductors such as poly(3-hexylthiophene) (P3HT) enables efficient charge transfer between the two materials for the production of hybrid graphene/ organic electronic devices. ${ }^{3,5}$ Successful integration of graphene and P3HT into OFETs, OPVs and other electronic devices has been recently demonstrated. ${ }^{3,5-8}$

\footnotetext{
${ }^{a}$ Nano-Engineered Materials \& Organic Electronics Laboratory, Umeå University, Umeå, Sweden. E-mail: david.barbero@umu.se

${ }^{b}$ Department of Physics, McGill University, Montréal, Québec, H3A 2T8, Canada

${ }^{c}$ Stanford Synchrotron Radiation Lightsource, Menlo Park, CA, USA

$\dagger$ Electronic supplementary information (ESI) available: Experimental procedures for preparation and characterization of the samples. See DOI: 10.1039/c6tc00625f
}

However, the performance of such hybrid devices relies in large part on the ability of the semiconducting polymer film to transport charges efficiently. The crystallinity of the organic semiconductor strongly influences its electronic properties, and it is therefore very important to be able to control not only the overall crystallinity of the film, but also the orientation of polymer crystallites. For example, P3HT tends to form in-plane $\pi-\pi$ stacking (edge-on lamellae) on weakly interacting surfaces (e.g. silicon oxide), which is useful for devices where charges must be transported in the plane of the film (e.g. OFETs). ${ }^{9-12}$ However, in order to produce efficient out-of-plane charge transport in a diode configuration (OLEDs or OPVs), a different crystalline orientation is usually required with $e . g$. vertical $\pi$ stacking (face-on orientation). ${ }^{10,13,14}$

Several studies performed on weakly interacting surfaces (e.g. $\mathrm{SiO}_{x}, \mathrm{TiO}_{2}$ ) have reported that a higher degree of crystallinity resulted in higher charge carrier mobility in polythiophene films. ${ }^{15,16}$ However, there are still very few experimental studies of polythiophenes on more strongly $\pi$ interacting surfaces such as single layer graphene. Simulations have predicted vertical $\pi$ stacking of P3HT on graphene due to $\pi-\pi$ interactions, while recent experimental results have shown that the thickness of the P3HT film plays an important role in the crystallite orientations on graphene. ${ }^{17,18}$ Very thin films $(\approx 10 \mathrm{~nm})$ produced better oriented face-on crystallites, whereas relatively thick films $(\approx 50 \mathrm{~nm}$ ) formed a mosaic of random crystallites with $\pi-\pi$ stacking oriented at all angles from the substrate normal, which enhanced charge transport across the film thickness. ${ }^{18}$ Moreover, the crystallinity of polythiophenes on weakly interacting surfaces has been shown to depend on the annealing temperature, and annealing is commonly used to improve both crystallinity and device efficiency in OPVs. ${ }^{19}$ However, it is still unknown how annealing on a more interacting substrate, such as single layer graphene, affects the interplay between crystallinity and charge transport in a P3HT film. In order to produce fast charge transport in a graphene/P3HT hybrid device, one needs to be able to control both the crystallinity and the crystallite orientation of the P3HT film on the graphene surface, and to understand how critical processing parameters (such as the annealing temperature) influence these. 


\section{Experimental section}

\section{Materials}

Poly-3-hexylthiophene (P3HT) $\left(98 \% \mathrm{RR}, M_{\mathrm{w}}=32 \mathrm{kD}\right)$ was purchased from American Dye Source Inc. The graphene sheets were synthesized on a copper foil by chemical vapor deposition (CVD) and transferred onto a silicon substrate by etching the copper and floating the graphene in DI water as explained in detail in previous publications. ${ }^{18,20}$ Raman spectroscopy was previously used to probe the monolayer character and coverage of the graphene sheet on silicon, and confirmed that these were single layer sheets of graphene. ${ }^{18}$ Details of the synthesis and transfer procedure of graphene and other materials used can be found in the ESI. $\dagger$

\section{Sample preparation}

P3HT films of $85 \mathrm{~nm}$ thick were spin-cast on the graphene/ silicon substrates from a dilute solution in dichlorobenzene and annealed in an inert nitrogen atmosphere at $200{ }^{\circ} \mathrm{C}$ and $240{ }^{\circ} \mathrm{C}$ for $15 \mathrm{~min}$, followed by slow cooling $\left(\approx 1{ }^{\circ} \mathrm{C} \mathrm{min}^{-1}\right)$ to room temperature. A schematic representation of the work functions of silicon, graphene and P3HT is shown in Fig. 2c.

\section{Synchrotron X-ray diffraction}

The samples were characterized by AFM (Veeco Multimode) for the determination of film thickness. The crystallinity of the P3HT films was measured by 2D Grazing-incidence X-ray diffraction carried out at the Stanford Synchrotron Radiation Lightsource (SSRL) (Menlo Park, CA, USA). The beam energy was $12.7 \mathrm{keV}$, and the incident angle $\alpha$ was either $0.13^{\circ}$ in order to probe the whole thickness of the $\mathrm{P} 3 \mathrm{HT}$ films or $0.08^{\circ}$ in order to probe the topmost layer of the P3HT films. All measurements were carried out in an inert atmosphere. See the ESI $\dagger$ for more details.

\section{Electrical characterization}

The conductivity and charge-carrier mobility of the P3HT films were measured in the vertical direction (diode configuration) using smooth and flexible silver top electrodes (see more details on the electrode preparation procedure in the ESI $\dagger$ ). The work function value of $-4.7 \mathrm{eV}$ was reported in the literature for silver, ${ }^{21,22}$ which is very close to the HOMO of $\mathrm{P} 3 \mathrm{HT}$ and therefore creates a very low potential barrier for the hole transport. This is also in accordance with our previous work, which showed good hole transport from P3HT to the silver top electrode. ${ }^{18}$ The current density $J$ was recorded as a function of the applied voltage $U$, and the mobility $(\mu)$ was extracted using both the classical Mott-Gurney $(\mathrm{M}-\mathrm{G})$ equation $(\text { eqn (1) })^{23}$ and the drift-diffusion (D-D) model (eqn (2) $)^{24,25}$ which describe the space-charge-limited current typically found in organic semiconductors:

$$
\begin{gathered}
\text { Mott - Gurney: } \mu=\frac{8 J L^{3}}{9 \varepsilon U^{2}} \\
\text { Drift - diffusion: } \mu=\frac{J L^{3}}{\varepsilon U\left(4 \pi^{2} \frac{k T}{q}+\frac{9}{8} U\right)}
\end{gathered}
$$

where $J$ is the current density, $U$ the applied voltage, $L$ the sample thickness, $\varepsilon$ the dielectric constant of the film, $k$ the Boltzmann constant, $T$ the temperature, and $q$ the elementary charge. The Drift-D model fitted the data better at low voltage in the diffusive regime and was used to report mobilities as shown in Fig. 2b.

\section{Results}

In this article, we characterized the crystallinity and the electronic properties of a highly regio-regular P3HT thin film deposited on a single layer graphene as a function of its annealing temperature, spanning below to above $T_{\mathrm{m}}$. Our results show that annealing at higher temperatures on graphene results in a less crystalline film with enhanced charge transport. These results are important to better understand the crystallization behavior of semiconducting polythiophene polymers on graphene and to better understand the interplay between crystallinity and charge carrier mobility for energy conversion devices.

The conductivity and charge-carrier mobility of the P3HT films were measured in the vertical direction (diode configuration) which is the same direction of current flow in an OPV or OLED. Indeed, the direction of charge transport in such films strongly depends on the crystallite orientation, and it is likely not the same in the horizontal in-plane direction as measured in a FET configuration. For specific applications (e.g. OPVs), it is important to know how charges flow in the vertical direction. The current flowing perpendicularly to the film was measured between two electrodes under a potential bias. A current density $J \approx 1.5 \pm$ $0.2 \mathrm{~A} \mathrm{~cm}^{-2}$ was measured in the film annealed at $200^{\circ} \mathrm{C}$, whereas $J \approx 2.4 \pm 0.2 \mathrm{~A} \mathrm{~cm}^{-2}$ was measured in the film annealed at $240{ }^{\circ} \mathrm{C}$, both at an applied bias of $3.5 \mathrm{~V}$. Room temperature vertical mobilities $\mu \approx 2.81 \pm 0.19 \times 10^{-4} \mathrm{~cm}^{2} \mathrm{~V}^{-1} \mathrm{~s}^{-1}$ and $\mu \approx 3.51 \pm 0.23 \times 10^{-4} \mathrm{~cm}^{2} \mathrm{~V}^{-1} \mathrm{~s}^{-1}$ were measured in the film annealed at $200{ }^{\circ} \mathrm{C}$ using the $\mathrm{D}-\mathrm{D}$ and the $\mathrm{M}-\mathrm{G}$ models, respectively, at saturation. When annealed at $240{ }^{\circ} \mathrm{C}$, the film exhibited mobilities $\mu \approx 4.15 \pm 0.37 \times 10^{-4} \mathrm{~cm}^{2} \mathrm{~V}^{-1} \mathrm{~s}^{-1}$ and $\mu \approx 5.18 \pm$ $0.46 \times 10^{-4} \mathrm{~cm}^{2} \mathrm{~V}^{-1} \mathrm{~s}^{-1}$ at saturation by the $\mathrm{D}-\mathrm{D}$ and the $\mathrm{M}-\mathrm{G}$ models respectively. These values are reported in Table 1. Therefore, better charge transport and higher mobility were measured in the film annealed above the melting point $\left(240{ }^{\circ} \mathrm{C}\right)$ compared to the one annealed below $\left(200{ }^{\circ} \mathrm{C}\right)$. Annealing to high temperatures has been previously shown to enhance the mobility in P3HT films deposited on silicon and glass/ITO (indium tin oxide) substrates covered with a conducting PEDOT/PSS layer. ${ }^{27}$ However, until today, it was not known how annealing above the melting point affects charge transport in P3HT deposited on a single layer of graphene, especially in the vertical direction which is necessary for diodes and photovoltaics. Moreover, graphene has been shown to produce stronger $\pi-\pi$ interactions with P3HT compared to silicon and other less interacting substrates, resulting in a different crystallinity. ${ }^{17}$ Therefore, the mechanism of charge transport in P3HT deposited on graphene may be different than that in previous studies of P3HT on less interacting surfaces. 
Table 1 Diffraction intensity values, vertical mobilities (estimated using the Mott-Gurney and drift-diffusion models), and their relative differences for the P3HT films on graphene annealed at $200{ }^{\circ} \mathrm{C}$ and $240{ }^{\circ} \mathrm{C}$

\begin{tabular}{llll}
\hline $\begin{array}{l}\text { Crystallinity and } \\
\text { mobility }\end{array}$ & $200{ }^{\circ} \mathrm{C}$ & $240{ }^{\circ} \mathrm{C}$ & $\begin{array}{l}\text { Difference when } \\
\text { increasing from } \\
200{ }^{\circ} \mathrm{C} \text { to } 240{ }^{\circ} \mathrm{C}(\%)\end{array}$ \\
\hline DoC (arb. units) & $1.94 \times 10^{6}$ & $1.30 \times 10^{6}$ & -33 \\
Edge-on (arb. units) & $1.83 \times 10^{5}$ & $1.94 \times 10^{5}$ & +6 \\
Face-on (arb. units) & $4.35 \times 10^{3}$ & $9.51 \times 10^{3}$ & +119 \\
$\mu_{\mathrm{M}-\mathrm{G}} \pm$ st. dev. & $3.51 \pm 0.23$ & $5.18 \pm 0.46$ & +48 \\
$\left(10^{-4} \mathrm{~cm}^{2} \mathrm{~V}^{-1} \mathrm{~s}^{-1}\right)$ & & & \\
$\mu_{\mathrm{D}-\mathrm{D}} \pm \mathrm{st}_{\text {dev. }}$ & $2.81 \pm 0.19$ & $4.15 \pm 0.37$ & +48 \\
$\left(10^{-4} \mathrm{~cm}^{2} \mathrm{~V}^{-1} \mathrm{~s}^{-1}\right)$ & & & \\
\hline
\end{tabular}

Since charge transport in semiconducting polymers such as P3HT strongly depends on its semicrystalline structure, we characterized these films by both $2 \mathrm{D}$ grazing incidence X-ray diffraction (2D GIXD) and specular X-ray diffraction. ${ }^{28-30}$ Measurement by GIXD provides a good estimate of crystallinity, the crystallite orientation and their coherence length inside the films. Different crystallite orientations are commonly found in regioregular P3HT as illustrated in Fig. 1b. The two most commonly reported are edge-on and face-on. In edge-on crystallites, $\pi-\pi$ stacking lies in the plane of the film, which is often found in P3HT deposited on weakly interacting substrates (silicon). ${ }^{13,19,31-33}$ In face-on crystallites, $\pi-\pi$ stacking is perpendicular to the substrate, and it is favored on substrates where $\pi$ interactions are stronger. The latter crystallite orientation is more favorable for transporting charges vertically through the vertical $\pi$ stacking.

The diffraction patterns of the highly regioregular P3HT films deposited on graphene and annealed at two different temperatures (200 and $240{ }^{\circ} \mathrm{C}$ ) are shown in Fig. 3. The incidence angle used $\left(\alpha=0.13^{\circ}\right)$ enabled probing the whole thickness of the sample, and the data shown in Fig. 3 are representative of the crystallinity inside the whole film. The films formed well-defined edge-on lamellae at both annealing temperatures as shown by the 3 strong (h00) diffraction peaks along the $z$ axis. Moreover, both films featured arcs of diffraction with intense regions near the specular $\left(q_{x y}=0\right.$ and $\left.\chi \approx 0^{\circ}\right)$ and in-plane $\left(q_{z}=0\right.$ and $\left.\chi \approx 90^{\circ}\right)$ directions. A (100) ring, which extends from $\chi \approx 0^{\circ}$ to $\approx 90^{\circ}$, is clearly visible in both films (see Fig. $3 \mathrm{a}$ and $\mathrm{b}$, close-ups) and indicates randomly oriented crystallites. The pole figures (Fig. 3c and d) show the distribution of the (100) diffracted intensity as a function of the $\chi$ angle and show that there is a larger number of tilted face-on lamellae (with a tilt angle $\approx 1-30^{\circ}$ from the substrate's plane) in the sample annealed at the higher temperature. The integrated intensity of the (100) ring represents the overall degree of crystallinity of the film, and is shown in Table 1 , along with other crystallinity parameters. From these data, it is clearly seen that the overall crystallinity in the films decreased by $33 \%$ upon increasing the temperature of annealing from $200{ }^{\circ} \mathrm{C}$ to $240{ }^{\circ} \mathrm{C}$. The number of
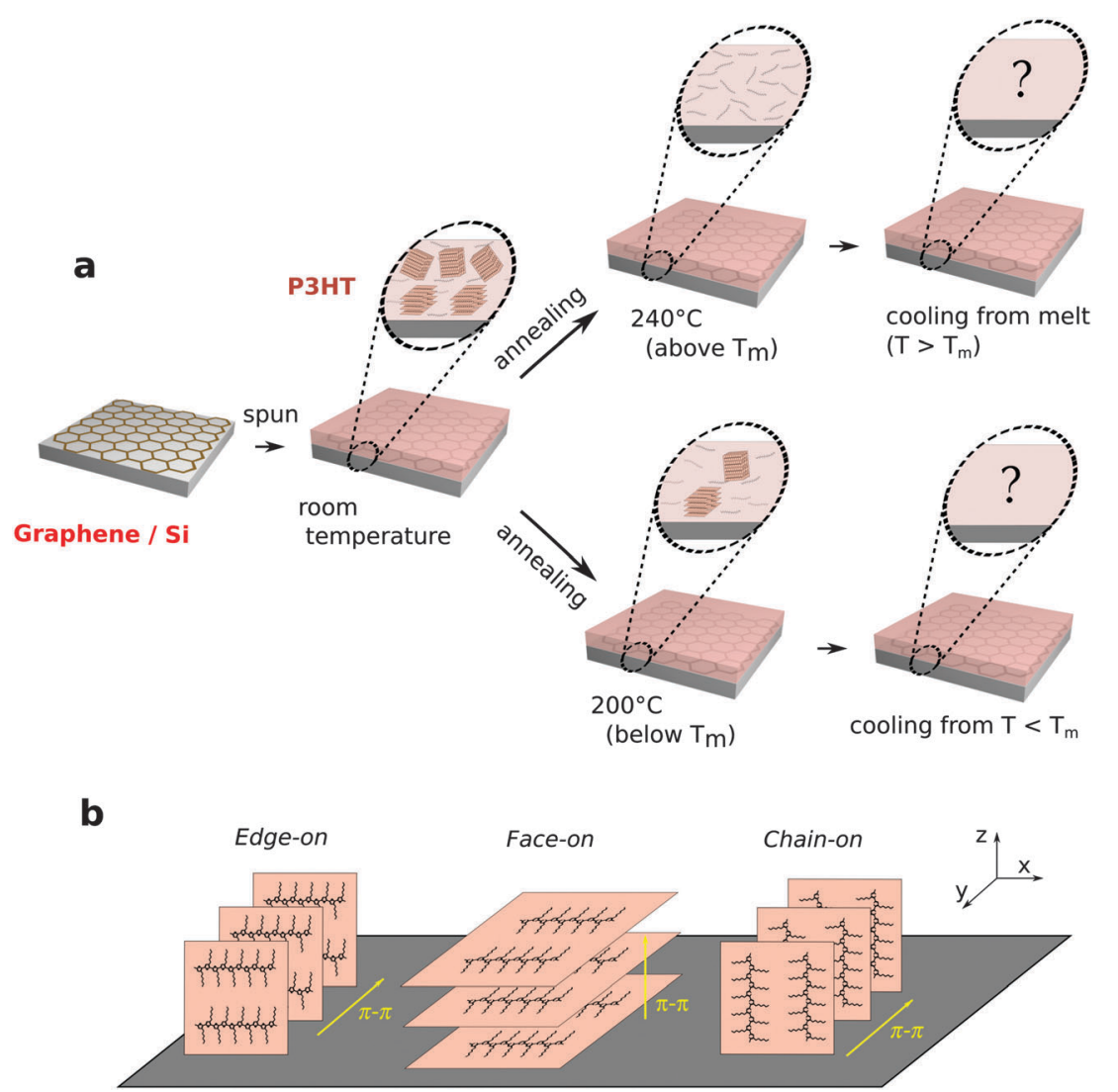

Fig. 1 Preparation and annealing of the graphene/P3HT samples. (a) The P3HT films were spun from solution, and annealed at either 200 or $240{ }^{\circ} \mathrm{C}$ before being cooled slowly to room temperature. (b) The three possible crystalline orientations in a P3HT film: edge-on, face-on or chain-on. 
a

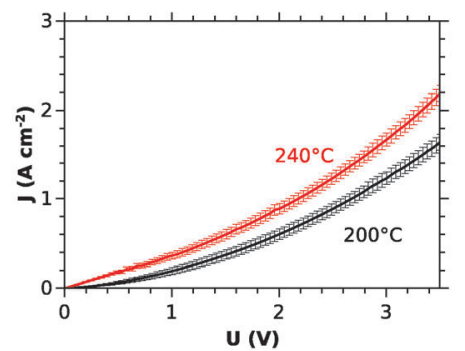

b

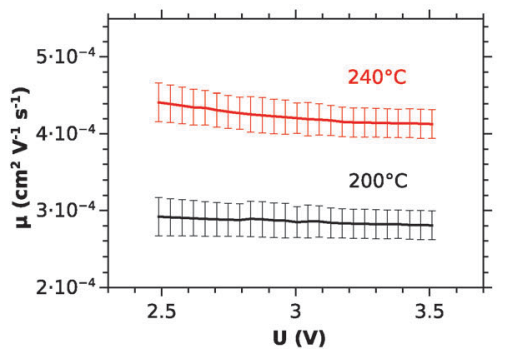

c

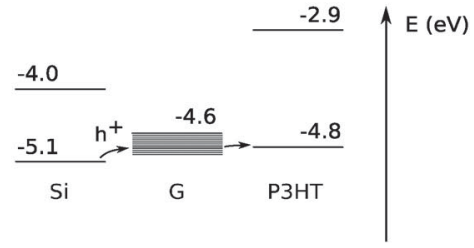

Fig. 2 Vertical current density and mobility in the P3HT films annealed at $200^{\circ} \mathrm{C}$ and $240{ }^{\circ} \mathrm{C}$ on graphene. (a) Current density-voltage characteristics of the films. (b) Room-temperature charge-carrier mobilities using the Drift-Diffusion model. The work functions of silicon, graphene and P3HT are displayed in (c), as well as hole injection from graphene to P3HT. It is likely that the pi-pi interaction between graphene and the thiophene rings of P3HT can lead to the doping of graphene with the polymer, resulting in the effective shift of the Fermi energy of graphene by approximately $0.2-0.3 \mathrm{eV}$. A similar effect has been shown for different polymers deposited on a single graphene sheet. ${ }^{26}$ For this reason, we have shown in dark grey a region where the graphene Fermi level is likely to be found, rather than an exact value.

a

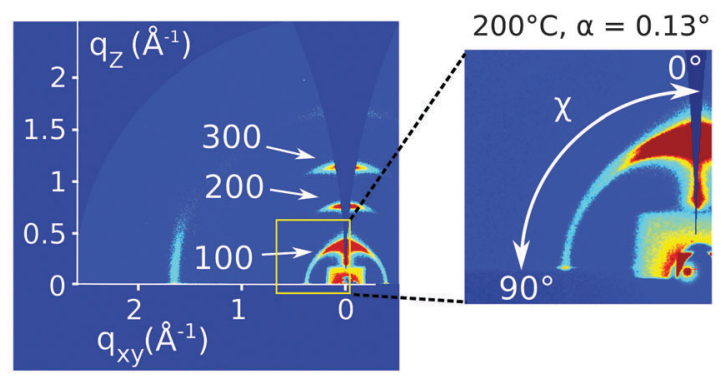

b

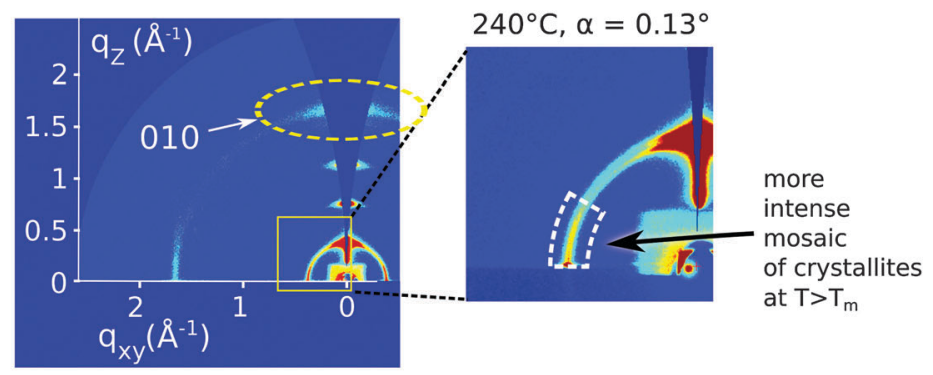

C

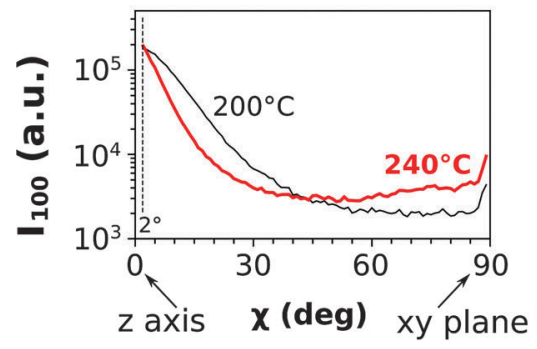

d

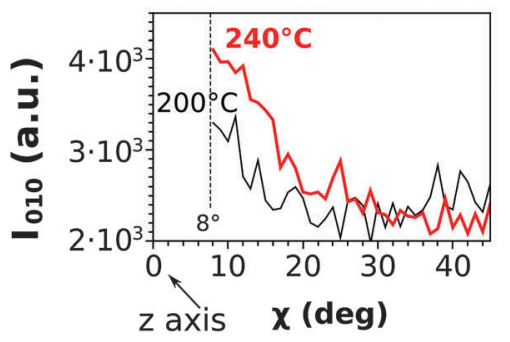

Fig. 3 Crystallinity in the whole $85 \mathrm{~nm}$ thick P3HT films at an incident beam incident angle $\alpha=0.13^{\circ}$. Panels (a) and (b) show 2D grazing incidence diffraction patterns of P3HT for a film annealed at (a) $200{ }^{\circ} \mathrm{C}$ and (b) $240{ }^{\circ} \mathrm{C}$. The magnified views in (a and b) show the (100) arc of diffraction and the $\chi$ angle. Panels (c) and (d) show the variation of the (100) and (010) integrated diffracted intensities, respectively, as a function of the $\chi$ angle in both samples (pole figures). It is seen in (c) that the number of edge-on lamellae is nearly the same at both temperatures. However, in (d), there is a clear increase in the number of (010) oriented lamellae at $240{ }^{\circ} \mathrm{C}$ compared to $200{ }^{\circ} \mathrm{C}$ near the $z$ axis. The background intensity was subtracted from the data shown in (c) and (d).

edge-on lamellae $\left(100_{z}\right)$ is however nearly the same at both temperatures, while the number of face-on lamellae $\left(100_{x y}\right)$ is more than double at $240{ }^{\circ} \mathrm{C}$ compared to that at $200^{\circ}$ (Fig. $3 \mathrm{c}$ and d and Table 1). The increased number of face-on lamellae with a small tilt angle $\approx 1-30^{\circ}$ of their $\pi$ stacking (with respect to the $x y$ plane's normal) in the film annealed at $240{ }^{\circ} \mathrm{C}$ is also clearly visible in Fig. 3b, as indicated by the boxes with broken lines (100 and 010 arcs of diffraction near the (xy) plane and the $z$ axis respectively).

Using a lower incidence beam angle $\alpha=0.08^{\circ}$ allowed us to probe the top surface of the films $(7-8 \mathrm{~nm})$ instead of the whole 
a

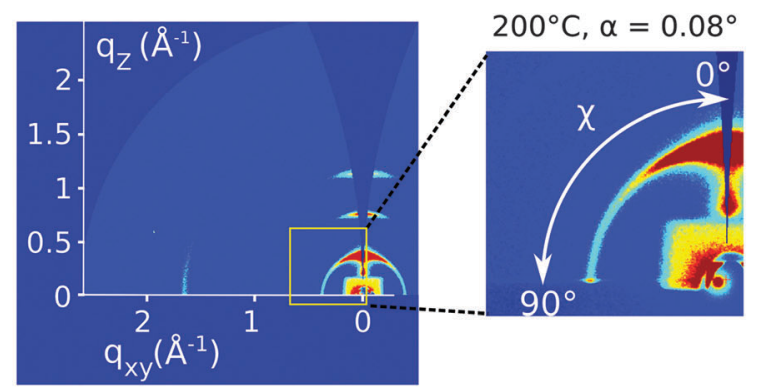

b

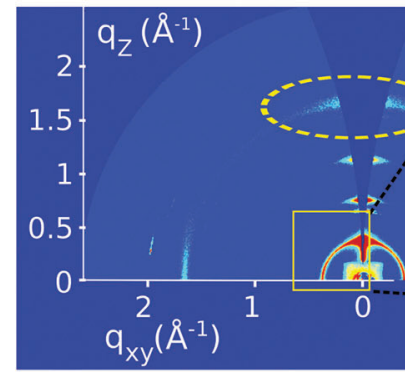

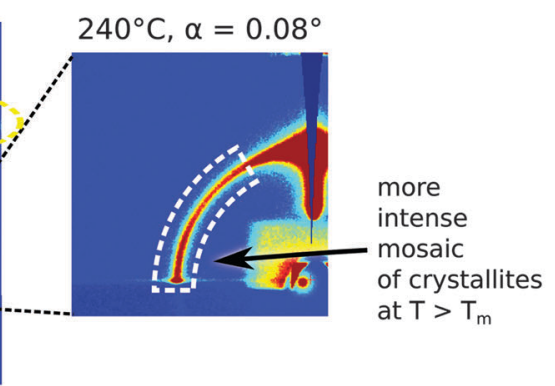
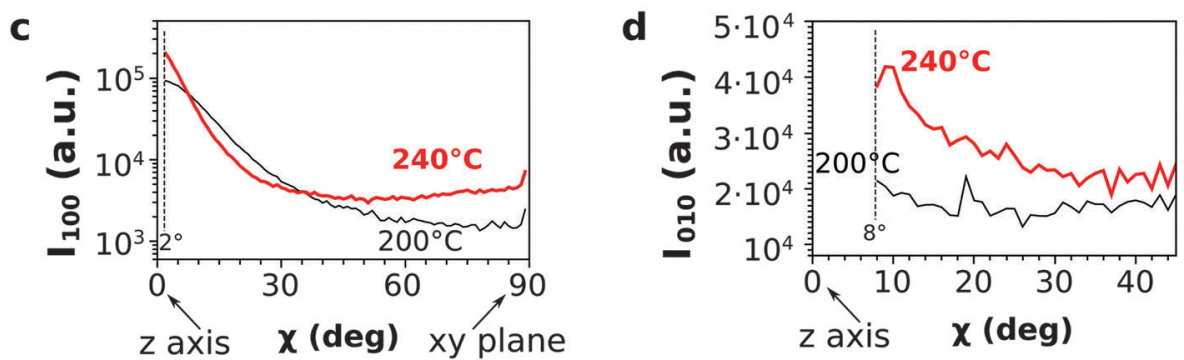

Fig. 4 Crystallinity near the top of the $85 \mathrm{~nm}$ thick P3HT films at a shallow beam incident angle $\alpha=0.08^{\circ}$. Panels (a) and (b) show 2D grazing incidence diffraction patterns of P3HT for a film annealed at (a) $200{ }^{\circ} \mathrm{C}$ and (b) $240{ }^{\circ} \mathrm{C}$. The magnified views in (a) and (b) show the (100) arc of diffraction. Panels (c) and (d) show the variation of the (100) and (010) integrated diffracted intensities, respectively, as a function of the $\chi$ angle in both samples (pole figures). The presence of a well defined (010) diffraction at $q_{z} \approx 1.65 \AA^{-1}$ is observed only in the sample annealed at $240{ }^{\circ} \mathrm{C}$ (see (b)). The background intensity was subtracted from the data shown in (c) and (d).

film thickness and to estimate the relative number of face-on crystallites at the free surface in both samples (see Fig. 4). A similar crystalline orientation was found at the top of the films compared to their bulk, with well-defined edge-on lamellae and (100) arcs of diffraction, but only the film annealed at $240{ }^{\circ} \mathrm{C}$ had significant face-on lamellae present at the top surface of the film (see Fig. $4 \mathrm{c}$ and d). The relative proportions of slightly tilted $\left(\chi<8^{\circ}\right)$ face-on crystallites to edge-on lamellae at the top and in the bulk of the films were estimated by measuring the ratio of diffracted intensities $\left(I_{(010)} / I_{(100)}\right)$ for the (010) and (100) peaks (shown in Table 2). The $I_{(010)} / I_{(100)}$ intensity ratio was estimated at two $\chi$ angles $\left(\chi \approx 8^{\circ}\right.$ near out of plane and $\chi \approx 89^{\circ}$ in plane). The data show that there is (relatively to the overall crystallinity)

Table 2 Intensity ratios $I_{(010)} / I_{(100)}$ (whole film and top layer) for P3HT on graphene. The $\chi$ angles are $8^{\circ}$ (close to out of plane) and $89^{\circ}$ (close to in plane)

\begin{tabular}{lrll}
\hline Thickness probed & $\chi\left({ }^{\circ}\right)$ & $200{ }^{\circ} \mathrm{C}$ & $240{ }^{\circ} \mathrm{C}$ \\
\hline Top layer & 8 & 0.035 & 0.067 \\
Top layer & 89 & 1.664 & 0.591 \\
Whole film & 8 & 0.029 & 0.076 \\
Whole film & 89 & 1.555 & 0.504
\end{tabular}

more than twice the number of face-on lamellae in the film annealed at $240{ }^{\circ} \mathrm{C}$ compared to the one annealed at $200{ }^{\circ} \mathrm{C}$. Moreover, the proportion of face-on in the top layer of the film annealed at $240{ }^{\circ} \mathrm{C}$ is nearly double that at $200{ }^{\circ} \mathrm{C}$.

\section{Discussion}

These results show that annealing at a higher temperature of $240{ }^{\circ} \mathrm{C}$ produces a different crystallinity in the film upon cooling down to room temperature, with a larger number of face-on aggregates and crystallites with their $\pi$ stacking orientated at low tilt angles $\left(\chi=60-89^{\circ}\right)$ from the substrate. These characteristics were observed both in the bulk and the top part of the film. This crystallite orientation has been shown to promote vertical charge transport in P3HT due to fast charge transport along the $\pi$ stacking inside the crystallites, and by enabling the formation of a better interconnected charge pathway between crystallites inside the film. ${ }^{18}$ We believe that the difference in crystallinity between the two films explains the higher mobility measured in the samples annealed at $240{ }^{\circ} \mathrm{C}$, and it is consistent 
a

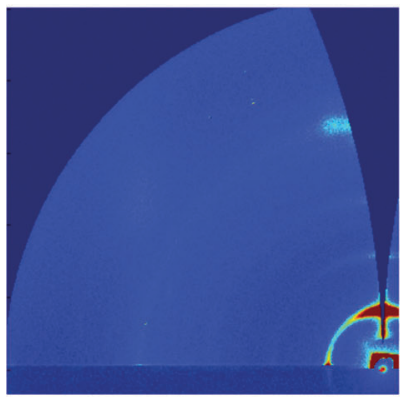

spun film, RT b

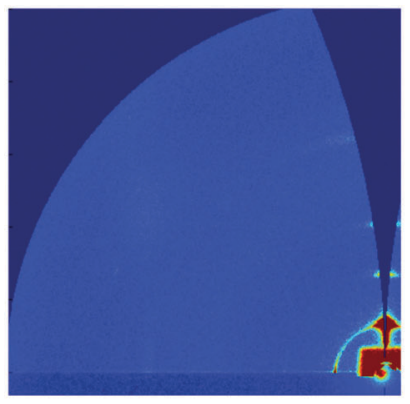

$200^{\circ} \mathrm{C}$

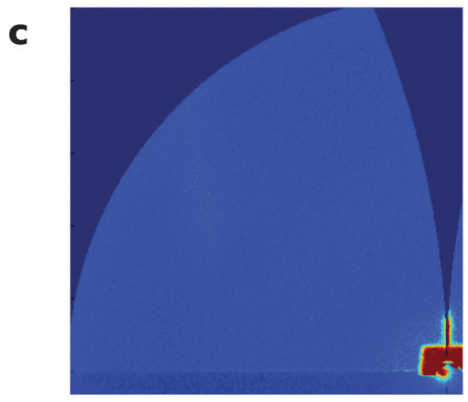

$240^{\circ} \mathrm{C}$

Fig. 5 Diffraction patterns of P3HT films on graphene at different annealing temperatures. (a) A spun film at room temperature; (b) the film is annealed at $200{ }^{\circ} \mathrm{C}$; and (c) annealing at $240{ }^{\circ} \mathrm{C}$ where the film is weakly crystalline.
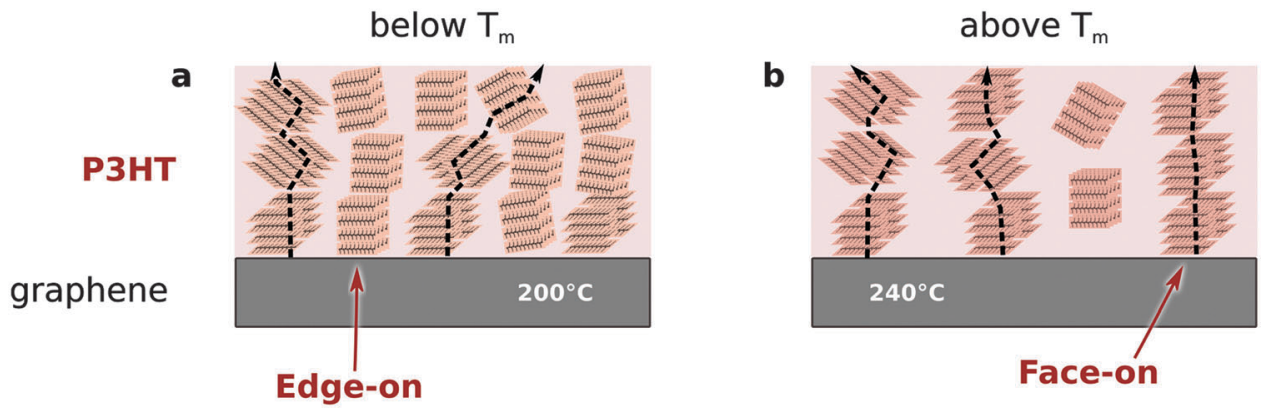

Fig. 6 Schematics of crystallites and charge transport in P3HT on graphene. (a) At $200{ }^{\circ} \mathrm{C}$ P3HT forms both edge-on and face-on (F) crystalline aggregates, but the face-on aggregates are mostly localized at the bottom of the film. (b) At $240{ }^{\circ} \mathrm{C}$ more face-on (F) crystalline aggregates are formed throughout the thickness of the film (both at the bottom and at the top) which enhances charge transport vertically with $\pi-\pi$ stacking perpendicular to the plane of the film. Both ( $a$ and $b$ ) possess a mosaic of crystallites oriented at various angles which also contribute to vertical charge transport.

with previous studies of P3HT crystallinity and charge transport. ${ }^{18}$ Here, we show that the charge carrier mobility in P3HT on graphene can be enhanced by more than $100 \%$ by annealing the film at higher temperatures $\left(240{ }^{\circ} \mathrm{C} v\right.$ s. $\left.170{ }^{\circ} \mathrm{C}\right)$. It is also worth noticing that the films studied here are slightly thicker than those previously used $(85 \mathrm{~nm} v s .50 \mathrm{~nm})$ and that they display higher mobility. Efficient charge transport through thicker films is advantageous for opto-electronic applications because the films need to be thick enough to absorb enough light, but also charges must be transported through longer distances, which can be a challenge.

In order to better understand the reasons for the different crystallite orientations in the film annealed at the two different temperatures, we recorded the diffraction patterns of the films during annealing. The results display the crystallinity in an $85 \mathrm{~nm}$ thick film spun at room temperature (Fig. 5a), $200{ }^{\circ} \mathrm{C}$ (Fig. 5b), and $240{ }^{\circ} \mathrm{C}$ (Fig. $5 \mathrm{c}$ ). As the temperature is increased, the crystallinity decreases (weaker diffraction patterns) in the film. At $240{ }^{\circ} \mathrm{C}$, the film becomes disordered and no diffraction pattern is visible; however, at $200{ }^{\circ} \mathrm{C}$ some crystallites are still present in the film, especially (100) edge-on lamellae. Therefore, upon cooling slowly from $200{ }^{\circ} \mathrm{C}$, the existing crystallites can act as seeds for the P3HT chains to form more crystallites with the same orientation. By contrast, when cooling from $240{ }^{\circ} \mathrm{C}$, there is no preferential orientation for the chains to start crystallization. Therefore, one should expect more face-on lamellae to be formed after annealing at this temperature due to the tendency of polythiophene chains to orientate themselves in a co-planar configuration through $\pi$ interactions with the graphene surface and to form face-on lamellae. ${ }^{17}$

From the synchrotron X-ray diffraction data, we now attempt to represent schematically the crystalline orientations (Fig. 6), and the possible charge transport pathways in the samples annealed either at 200 or $240{ }^{\circ} \mathrm{C}$. At $200^{\circ} \mathrm{C}$ the sample is composed of a mixture of edge-on and face-on lamellae (Fig. 6a), with a fairly large proportion of crystallites orientated at different angles from the substrate ((100) arc of diffraction). Face-on lamellae are found mainly in the bulk, but not near the top of the film, therefore charge transport is principally due to the mosaic of random crystalline orientations which form an interconnected path from the top to the bottom of the film where charges can be transported along the $\pi-\pi$ stacking oriented at many different angles. Upon annealing at $240{ }^{\circ} \mathrm{C}$, the film retains a similar crystalline structure with an even more pronounced mosaic of crystallites oriented at different angles (Fig. 6b), but also with a larger proportion of face-on lamellae than at $200{ }^{\circ} \mathrm{C}$, which enhances charge transport vertically. The larger number of face-on lamellae near the top of the film can also favor charge injection and extraction from this interface.

\section{Conclusions}

In conclusion, we have studied the crystallinity and charge transport properties of a thin semiconducting P3HT film deposited on 
top of a single layer graphene sheet and annealed at two different temperatures (above and below the melting point of P3HT). It is found that the higher annealing temperature produces a less crystalline film, with a larger number of face-on lamellae both in the bulk and near the top of the film. This increased vertical $\pi$ stacking and the formation of an interconnected path of crystallites across the film thickness translate into an enhanced vertical charge transport and higher charge carrier mobilities, despite the film being overall less crystalline. The control of annealing temperature on graphene substrates may therefore help better control the crystallinity of P3HT films and may be used to produce more efficient OPVs and OLEDs.

\section{Acknowledgements}

Portions of this research were carried out at the Stanford Synchrotron Radiation Lightsource, a Directorate of SLAC National Accelerator Laboratory and an Office of Science User Facility operated for the U.S. Department of Energy Office of Science by Stanford University. Some sample preparation was performed at MyFab (Angström Laboratory) at Uppsala University. The authors thank the Baltic Foundation, the Helge Ax:son Johnsons Foundation and the Kempe Foundation for financial support. D. R. B. also thanks a Young Researcher Career Award from Umeå University for support of this work.

\section{References}

1 K. S. Novoselov, A. K. Geim, S. V. Morozov, D. Jiang, Y. Zhang, S. V. Dubonos, I. V. Grigorieva and A. A. Firsov, Science, 2004, 306, 666-669.

2 B. Obradovic, R. Kotlyar, F. Heinz, P. Matagne, T. Rakshit, M. D. Giles, M. A. Stettler and D. E. Nikonov, Appl. Phys. Lett., 2006, 88, 142102.

3 Z. Liu, Q. Liu, Y. Huang, Y. Ma, S. Yin, X. Zhang, W. Sun and Y. Chen, Adv. Mater., 2008, 20, 3924-3930.

4 L. Wang, I. Meric, P. Y. Huang, Q. Gao, Y. Gao, H. Tran, T. Taniguchi, K. Watanabe, L. M. Campos, D. A. Muller, J. Guo, P. Kim, J. Hone, K. L. Shepard and C. R. Dean, Science, 2013, 342, 614-617.

5 L. Zhang, Y. Li, J. Shi, G. Shi and S. Cao, Mater. Chem. Phys., 2013, 142, 626-632.

6 Y.-C. Lai, Y.-X. Wang, Y.-C. Huang, T.-Y. Lin, Y.-P. Hsieh, Y.-J. Yang and Y.-F. Chen, Adv. Funct. Mater., 2013, 24, 1430-1438.

7 Y. Wu, X. Zhang, J. Jie, C. Xie, X. Zhang, B. Sun, Y. Wang and P. Gao, J. Phys. Chem. C, 2013, 117, 11968-11976.

8 J. Huang, D. R. Hines, B. J. Jung, M. S. Bronsgeest, A. Tunnell, V. Ballarotto, H. E. Katz, M. S. Fuhrer, E. D. Williams and J. Cumings, Org. Electron., 2011, 12, 1471-1476.

9 G. Wang, J. Swensen, D. Moses and A. J. Heeger, J. Appl. Phys., 2003, 93, 6137-6141.

10 H. Yang, T. Shin, L. Yang, K. Cho, C. Ryu and Z. Bao, Adv. Funct. Mater., 2005, 15, 671-676.

11 M. Surin, P. Leclère, R. Lazzaroni, J. D. Yuen, G. Wang, D. Moses, A. J. Heeger, S. Cho and K. Lee, J. Appl. Phys., 2006, 100, 033712.
12 D. Gargi, R. J. Kline, D. M. DeLongchamp, D. A. Fischer, M. F. Toney and B. T. O'Connor, J. Phys. Chem. C, 2013, 117, 17421-17428.

13 L. H. Jimison, S. Himmelberger, D. T. Duong, J. Rivnay, M. F. Toney and A. Salleo, J. Polym. Sci., Part B: Polym. Phys., 2013, 51, 611-620.

14 W. Porzio, G. Scavia, L. Barba, G. Arrighetti and S. Milita, Eur. Polym. J., 2011, 47, 273-283.

15 B. Hamadani, D. Gundlach, I. McCulloch and M. Heeney, Appl. Phys. Lett., 2007, 91, 3512.

16 I. McCulloch, M. Heeney, C. Bailey, K. Genevicius, I. MacDonald, M. Shkunov, D. Sparrowe, S. Tierney, R. Wagner and W. Zhang, et al., Nat. Mater., 2006, 5, 328-333.

17 D. H. Kim, H. S. Lee, H.-J. Shin, Y.-S. Bae, K.-H. Lee, S.-W. Kim, D. Choi and J.-Y. Choi, Soft Matter, 2013, 9, 5355-5360.

18 V. Skrypnychuk, N. Boulanger, V. Yu, M. Hilke, S. C. B. Mannsfeld, M. F. Toney and D. R. Barbero, Adv. Funct. Mater., 2015, 25, 664-670.

19 E. Verploegen, R. Mondal, C. J. Bettinger, S. Sok, M. F. Toney and Z. Bao, Adv. Funct. Mater., 2010, 20, 3519-3529.

20 D. R. Cooper, B. D’Anjou, N. Ghattamaneni, B. Harack, M. Hilke, A. Horth, N. Majlis, M. Massicotte, L. Vandsburger, E. Whiteway and V. Yu, ISRN Condens. Matter Phys., 2012, 2012, 501686.

21 P. Wang, D. Tanaka, S. Ryuzaki, S. Araki, K. Okamoto and K. Tamada, Appl. Phys. Lett., 2015, 107, 151601.

22 J.-P. Hong, A.-Y. Park, S. Lee, J. Kang, N. Shin and D. Y. Yoon, Appl. Phys. Lett., 2008, 92, 143311.

23 R. W. G. N. F. Mott, Electronic Processes in Ionic Crystals, Dover Publications, New York, USA, 1964.

24 P. de Bruyn, A. H. P. van Rest, G. A. H. Wetzelaer, D. M. de Leeuw and P. W. M. Blom, Phys. Rev. Lett., 2013, 111, 186801.

25 G. A. H. Wetzelaer and P. W. M. Blom, Phys. Rev. B: Condens. Matter Mater. Phys., 2014, 89, 241201.

26 J. M. Yun, S. Park, Y. H. Hwang, E.-S. Lee, U. Maiti, H. Moon, B.-H. Kim, B.-S. Bae, Y.-H. Kim and S. O. Kim, ACS Nano, 2014, 8, 650-656.

27 C. R. Singh, G. Gupta, R. Lohwasser, S. Engmann, J. Balko, M. Thelakkat, T. Thurn-Albrecht and H. Hoppe, J. Polym. Sci., Part B: Polym. Phys., 2013, 51, 943-951.

28 J. Rivnay, S. C. B. Mannsfeld, C. E. Miller, A. Salleo and M. F. Toney, Chem. Rev., 2012, 112, 5488-5519.

29 D. M. DeLongchamp, R. J. Kline, D. A. Fischer, L. J. Richter and M. F. Toney, Adv. Mater., 2011, 23, 319-337.

30 J. L. Baker, L. H. Jimison, S. Mannsfeld, S. Volkman, S. Yin, V. Subramanian, A. Salleo, A. P. Alivisatos and M. F. Toney, Langmuir, 2010, 26, 9146-9151.

31 T. Salammal Shabi, S. Grigorian, M. Brinkmann, U. Pietsch, N. Koenen, N. Kayunkid and U. Scherf, J. Appl. Polym. Sci., 2012, 125, 2335-2341.

32 G. Scavia, W. Porzio, S. Destri, L. Barba, G. Arrighetti, S. Milita, L. Fumagalli, D. Natali and M. Sampietro, Surf. Sci., 2008, 602, 3106-3115.

33 D. M. DeLongchamp, R. J. Kline, Y. Jung, E. K. Lin, D. A. Fischer, D. J. Gundlach, S. K. Cotts, A. J. Moad, L. J. Richter, M. F. Toney, M. Heeney and I. McCulloch, Macromolecules, 2008, 41, 5709-5715. 